\title{
Hypocalcaemia as an important differential diagnosis in patients suffering from stridor following thyroidectomy
}

\author{
Christine Nitschke ${ }^{1}$, Tarek Ghadban ${ }^{1}$, Jakob R. Izbicki ${ }^{1}$, and Rainer Grotelüschen ${ }^{1}$ \\ ${ }^{1}$ University Medical Center Hamburg-Eppendorf
}

June 20, 2020

\begin{abstract}
We present the case of an adult patient with acute dyspnoea and stridor following thyroidectomy. After excluding other causes of postoperative stridor, we concluded the patient was suffering from laryngospasm due to hypocalcaemia secondary to postoperative hypoparathyroidism. It is important to consider hypocalcaemia as a differential diagnosis in stridor.
\end{abstract}

\section{Hosted file}

Case Report Hypocalcaemia Upload final.pdf available at https://authorea.com/users/335266/ articles/461101-hypocalcaemia-as-an-important-differential-diagnosis-in-patientssuffering-from-stridor-following-thyroidectomy 